Bohlius, J. 55

Djulbegovic, B. 8

Engert, A. 32

Gafter-Gvili, A. 23, 39, 47, 80

Gale, R.P. 91

Galeb, S. 8

Goldberg, E. 80

Gurion, R. 68

Herbst, C. 32

Kumar, A. 8

Lazarus, H.M. 91
Paul, M. 80

Raanani, P. 5, 39, 47, 68

Ram, R. 39, 47

Schwarzer, G. 55

Shacham-Abulafia, A. 68

Shpilberg, O. 23, 39, 47, 68

Skoetz, N. 5

Tonia, T. 55

Vidal, L. 23

Yahav, D. 80

\title{
Subject Index Vol. 125, No. 1-2, 2011
}

Allogeneic hematopoietic cell

transplantation 39

- transplantation 47

Antibiotics 80

Antifungals 80

Antithymocyte globulin 47

Antivirals 80

Aplastic anemia 47

Autologous hematopoietic stem cell transplant 8

- stem cell transplant 39

Bisphosphonates 8

Cancer-related anemia 55

Chemoradiotherapy 32

Chemotherapy 32

Combined-modality treatment 32

Cyclosporine 47

Early-stage lymphoma 32

Epoetin 55

Erythropoiesis-stimulating agents 55

Expert opinion 91

Follicular lymphoma 23

G-CSF 68

Genetically randomized trials 39

GM-CSF 68
Hematopoietic growth factors 47

Hemoglobin 55

Hodgkin lymphoma 32

Infection control 80

Interferon 8,23

${ }^{131}$ I-tositumomab 23

Leukemia 39, 68

Lymphoma 68

Meta-analyses 39, 91

Meta-analysis 47, 68, 80

Multiple myeloma 8

Observational databases 91

Prophylaxis 80

Radiotherapy 32

Randomized clinical trials 91

Red blood cell transfusion 55

Rituximab 23

Systematic review $47,68,80$

Thalidomide 8

Thromboembolic events 55

Transplantation 39

${ }^{90}$ Y-ibritumomab tiuxetan 23

(c) 2010 S. Karger AG, Basel 